\title{
Prospects for the creation of smart homes using energy-saving wall ceramic materials
}

\author{
Alla Turchenko ${ }^{1, *}$, Tatiana Davydova ${ }^{1}$, and Irina Spivak $^{1}$ \\ ${ }^{1}$ Voronezh State Technical University, Moscovskiy prospect, 14, 394026, Voronezh, Russia
}

\begin{abstract}
The article discusses the prospects of energy saving in a 'smart home', taking into account the characteristics of consumer behavior. It is shown that the technical characteristics of the building in conditions of insufficient consumer awareness (passive approach to energy conservation) are preferable to the characteristics associated with intelligent solutions (active approach). It was revealed that special attention is paid to assessing the possibility of reducing the energy loss of a building by wall enclosures. In this regard, the effectiveness of the use of popular wall structural and heat-insulating materials, which reduce energy and material consumption in their production, is analyzed. The rationality of the production of porous ceramic products by the method of introducing into the mixture of mineral pore-forming additives with plastic molding is proved. A composition of porous ceramic material has been developed using local raw materials to create wall structural and heat-insulating products that meet the requirements of energy conservation.
\end{abstract}

\section{Introduction}

According to the decision of the European Union, over the next few years, the energy supply system for homes should become more efficient. Moreover, under the conditions of active development and implementation of innovative technologies, the theory and practice of "smart cities" and "smart homes" comes to the fore.

"Smart Home" is focused on meeting the needs of residents, meeting their needs and comfort. Among the priority tasks of their effective functioning is energy conservation. According to published data, buildings make up $35 \%$ of the total final demand for electricity [1]. Existing technologies allow you to create a system that optimizes the use of energy in homes [2], but its implementation should be carried out taking into account preferences and specific consumer behavior. Moreover, the consumer, using the results of the activities of the "smart environment", is at the same time an active participant in its formation [3].

The analysis shows that there are differences in the development of smart energy consumption environments for urban commercial and residential buildings [4, 5]. In particular, developments for the residential sector are less common.

\footnotetext{
* Corresponding author: allaevgen@mail.ru
} 
A certain contradiction is noted in the scientific literature regarding consumer behavior in the "smart home" system. It consists, on the one hand, in a clear interest, and on the other, in a lack of understanding by people of relevant intellectual technologies [6]. "Smart Home" is a tool for consumers interested in innovations and thinking about increasing the value of their property. It often turns out that the incorporated functionality is not really in demand. Accordingly, there is a need to integrate consumer preferences into smart technologies [7] depending on a number of factors: economic, social, geographical, educational level.

The importance of encouraging consumers to use less electricity is scientifically proven. There are two approaches to energy conservation in relation to consumer behavior [8]. The first is monetary stimulus, which is manifested in the growth of tariffs. It is most effective in countries with low fossil fuel reserves (European Union countries, Japan) and high energy prices. The second is information support. It is considered in two aspects: on the one hand, there is information about the environmental effect of energy conservation, and on the other, consultations on the correct assessment of the power of various household appliances. Such energy conservation is active from the position of direct participation of consumers in the process of energy conservation. Moreover, the results of the study [9] demonstrate clear differences in receiving feedback from respondents living in houses and residents of apartments. In the first case, a stronger bond is noted.

So, in particular, the data on monitoring the innovative behavior of the population of the National Research University of the Higher School of Economics indicate that the demand of Russians for new technologies is relatively low. None of the presented technological solutions interested more than half of the respondents. Citizens showed the most significant interest in the household solar battery installed on the roof of the house $(51 \%)$, household sensors of environmental pollution, warning about the presence of harmful substances in air or water $(50 \%)$. Almost half of the respondents motivated their refusal to use technological innovations by the fact that they do not feel the need for them [6].

Energy savings due to design decisions in the design and construction of buildings are defined as passive. The potential for energy saving with a passive approach depends on the physical characteristics of the building and on the thermal preferences of residents. The determining factors of the building's thermal loads are the used building materials, the type of glazing and the zoning of the building [10]. In addition, the temperature of residence is determined by the temperature of the outside air, external relative humidity, and the geographical orientation of the apartment. The integration of understanding consumer behavior in "smart technologies" leads to the conclusion that at the moment it is advisable to focus on constructive solutions to reduce energy consumption when creating "smart homes".

As part of the development and adoption of strategies to reduce energy consumption, types of energy-efficient walls, including ventilated and glazed ones, are discussed. The energy efficiency of the building is associated with a decrease in the heat transfer coefficient, while various types of heat-insulating materials are taken into account [11]; importance is given to the coefficients of solar gain and solar absorption of external coatings [12].

\section{Materials and methods}

The results of the study of scientific literature show that particular attention is paid to the development and improvement of building heat-insulating materials. Data are given that testify to the prospects of energy-saving and water-saving brick production technology [13]. The issues of preservation and reconstruction of mainly brick buildings included in 
the category of historical heritage, taking into account their thermal conductivity, are considered [14].

Based on the analysis, we propose to consider two approaches to energy conservation without and with the participation of consumers (Fig. 1).

\begin{tabular}{|c|c|c|}
\hline $\begin{array}{l}\text { Passive energy saving } \\
\text { without consumers }\end{array}$ & \multicolumn{2}{|c|}{$\begin{array}{c}\text { Active energy saving } \\
\text { with the participation of consumers }\end{array}$} \\
\hline Constructive decisions & Monetary stimulation & Information Support \\
\hline $\begin{array}{l}\text { The use of energy-saving building materials } \\
\text { (thermal conductivity, profitability, } \\
\text { environmental friendliness, durability) }\end{array}$ & \multirow{3}{*}{ Tariff growth } & \multirow[t]{2}{*}{ Environmental aspect } \\
\hline $\begin{array}{c}\text { Spatial and geographical location of } \\
\text { premises }\end{array}$ & & \\
\hline $\begin{array}{l}\text { Greening of building envelopes and adjacent } \\
\text { territories }\end{array}$ & & Power Device Consulting \\
\hline It is applied in all countries of the world & \multicolumn{2}{|c|}{ Applies to most European countries } \\
\hline 'Smart home' saves energy on its own & $\begin{array}{l}\text { Ineffective in countries with } \\
\text { rich energy reserves }\end{array}$ & $\begin{array}{l}\text { Effectiveness depends } \\
\text { heavily on consumer } \\
\text { culture }\end{array}$ \\
\hline
\end{tabular}

Fig. 1. 'Smart Home' energy saving approaches for consumer behavior.

In foreign countries, a large number of energy-efficient passive and active buildings are being built. In modern economic conditions, a long-term gap in the levels of energy efficiency with advanced countries is unacceptable [15]. In order to develop an effective energy saving strategy in Russia, it is useful to analyze the experience of countries such as Japan, the USA and European countries, where sufficiently effective mechanisms for stimulating energy conservation already exist. Taking into account the rich experience of developed countries in pursuing energy-saving policies, it can be concluded that a comprehensive approach is needed to successfully solve energy-saving problems, since improving one element will not allow drastically reducing energy consumption across the whole country [15].

Theoretically, energy-saving consumer behavior is more important than assessing the energy efficiency of homes in determining the efficiency of use of thermal energy [8]. However, a serious problem is to motivate household representatives to realize this significant potential. In countries with rich energy reserves (USA, Australia, Russia), monetary stimulation is not always effective enough, and information support is not always and everywhere is established and in demand. Therefore, in such conditions it is advisable to focus on the energy needs of "smart homes" in relation to constructive solutions in their design. At the same time, priority is given to materials that allow you to get returns in several directions.

When assessing the possibility of reducing the energy loss of a building, special attention is paid to walling. It is from this position that we propose to consider the prospects of creating "smart homes" using effective energy-saving materials that will reduce energy and material consumption in their production.

The following tasks are solved in the work: identifying the most competitive wall thermal insulation and structural material, determining a rational method for its production, developing a composition for a porous wall material based on local raw materials.

Today's market for building thermal insulation and structural wall materials is characterized by a wide selection. The most widespread among heat-insulating structural 
wall materials were: gas silicate and foam concrete blocks, as well as porous ceramic stones.

To compare the performance of products competing in the market of wall structural heat-insulating materials, we compile a table (Table 1). As a reference, we take an abstract product that has the best values of indicators from all groups included in the comparison database.

Table 1. Comparative characteristics of foam concrete, gas silicate and porous ceramic stone.

\begin{tabular}{|c|c|c|c|c|c|}
\hline Type of material & $\begin{array}{c}\text { Mark } \\
\text { by } \\
\text { average } \\
\text { density }\end{array}$ & $\begin{array}{c}\text { Mark } \\
\text { by } \\
\text { strength }\end{array}$ & $\begin{array}{c}\text { Mark } \\
\text { frost } \\
\text { resistance }\end{array}$ & $\begin{array}{c}\text { Thermal } \\
\text { conductivity } \\
\text { coefficient, } \boldsymbol{\lambda}_{\mathbf{0}} \\
\mathbf{W} /\left(\mathbf{m}{ }^{\circ} \mathbf{C}\right)\end{array}$ & $\begin{array}{c}\text { Shrinkage, } \\
\mathbf{( \% \mathbf { m m } /} \\
\mathbf{m})\end{array}$ \\
\hline Foam concrete & $\mathrm{D} 700$ & $\mathrm{M} 15$ & $\mathrm{~F} 15 ;$ & 0.18 & 2.1 \\
\hline G20 & $\mathrm{F} 25$ & $\mathrm{~F} 35$ & 0.17 & 1.5 \\
\hline $\begin{array}{c}\text { Porous ceramic } \\
\text { stone }\end{array}$ & $\mathrm{D} 700$ & $\mathrm{M} 100$ & $\mathrm{~F} 35$ & 0.17 & 0 \\
\hline
\end{tabular}

Comparison of the main indicators of heat-insulating structural wall building materials revealed that porous ceramic stones are the most competitive product in the market of building materials [16]. As a result of a marketing study, it was found that the market for porous ceramic stones is a growing type, while it is oligopolistic with a small number of leading manufacturers.

The analyzed domestic market of porous ceramic stones is a growing type with an average annual rate of change in consumption of 2,44 million standard bricks. This shows the positive dynamics of the market [16].

These stones have established themselves as a promising wall material, characterized by durability, fire resistance, environmental friendliness, architectural expressiveness, good sound-insulating ability. They are used in the construction of external walls and partitions of buildings for various purposes. The porosity of the ceramic crock varies widely from $15 \%$ to $60-80 \%$. The voidness of porous wall ceramic products for stones is $22-52 \%$, for hollow bricks - $15-50 \%$. In foreign countries they produce stones with a voidness of $62 \%$.

Table 2. Technological methods for creating the porous structure of ceramic wall products.

\begin{tabular}{|c|c|c|c|c|c|}
\hline $\begin{array}{c}\text { Way } \\
\text { pore formation }\end{array}$ & $\begin{array}{c}\text { The } \\
\text { volume of } \\
\text { created } \\
\text { porosity, } \%\end{array}$ & $\begin{array}{l}\text { Applied raw } \\
\text { material } \\
\text { preparation } \\
\text { method } \\
\end{array}$ & $\begin{array}{c}\text { Molding } \\
\text { moisture, } \\
\%\end{array}$ & $\begin{array}{c}\text { Molding } \\
\text { method }\end{array}$ & $\begin{array}{l}\text { The technological } \\
\text { stage of the } \\
\text { formation of the } \\
\text { porous structure }\end{array}$ \\
\hline $\begin{array}{l}\text { 1. Selection of the grain } \\
\text { composition of a } \\
\text { narrowly fractionated } \\
\text { filler }\end{array}$ & Up to 40 & Semi dry & $6-10$ & Pressing & $\begin{array}{l}\text { Raw material } \\
\text { preparation, } \\
\text { mixing, } \\
\text { Molding }\end{array}$ \\
\hline \multirow{2}{*}{$\begin{array}{c}\text { 2. Maintenance and } \\
\text { subsequent removal of } \\
\text { additives }\end{array}$} & \multirow[t]{2}{*}{ Up to 25} & Semi dry & $6-10$ & Pressing & \multirow[b]{2}{*}{ Burning } \\
\hline & & Plastic & $18-24$ & Extrusion & \\
\hline $\begin{array}{l}\text { 3. The introduction of } \\
\text { mineral pore-forming } \\
\text { additives }\end{array}$ & Up to 40 & Plastic & $18-24$ & Extrusion & Burning \\
\hline $\begin{array}{l}\text { 4. The introduction of } \\
\text { separately prepared } \\
\text { foam }\end{array}$ & Up to 95 & Slip & $38-48$ & Casting & Stirring \\
\hline $\begin{array}{c}\text { 5. Introducing a blowing } \\
\text { agent }\end{array}$ & Up to 85 & Slip & $38-48$ & Casting & Shuffling, Forming \\
\hline
\end{tabular}


In this study, a method of introducing mineral pore-forming additives was implemented (3 Table 2).

Loam of the Voronezh region was used as the main raw material. This raw material is medium plastic $(\mathrm{P}=24,5 \%)$ and is characterized by a binding ability of $20 \%$ [17].

The following mineral constituents were used: two-water gypsum $\left(\mathrm{CaSO}_{4} \times 2 \mathrm{H}_{2} \mathrm{O}\right)$, dense limestone $\left(\mathrm{CaCO}_{3}\right)$ of the Stanovlyansky district of the Lipetsk region, metallurgical slag of the Novolipetsk Metallurgical Plant (NLMP). The chemical composition of raw materials is presented in Table 3.

Table 3. The chemical composition of raw materials.

\begin{tabular}{|l|c|c|c|c|c|c|c|c|}
\hline \multirow{2}{*}{$\begin{array}{l}\text { View raw } \\
\text { material }\end{array}$} & \multicolumn{7}{|c|}{ Chemical composition. mass. \% } \\
\cline { 2 - 9 } & $\mathbf{S i O}_{2}$ & $\mathbf{A l}_{\mathbf{2}} \mathbf{O}_{\mathbf{3}}$ & $\mathbf{F e}_{\mathbf{2}} \mathbf{O}_{\mathbf{3}}$ & $\mathbf{\mathbf { T i O } _ { 2 }}$ & $\mathbf{C a O}$ & $\mathbf{M g O}$ & $\mathbf{N a}_{\mathbf{2}} \mathbf{O}+\mathbf{K}_{\mathbf{2}} \mathbf{O}$ & $\mathbf{R}_{\mathbf{2}} \mathbf{O}_{\mathbf{3}}$ \\
\hline $\begin{array}{l}\text { Dusty hydromica } \\
\text { clay }\end{array}$ & 51.43 & 14.65 & 4.50 & 0.45 & 8.0 & 3.78 & 4.33 & 19.1 \\
\hline $\begin{array}{l}\text { Metallurgical slag } \\
\text { NLMT }\end{array}$ & 9.85 & 4.0 & 9.7 & - & 51.1 & 6.25 & - & - \\
\hline
\end{tabular}

The choice of these additives is associated with the provision of the process of pore formation during firing at a temperature in the period before and during isothermal exposure of ceramic wall products $\left(900-1000{ }^{\circ} \mathrm{C}\right)$.

The preparation of the charges included the following stages: drying and grinding of the components until they completely passed through a No. 063 sieve for clay raw materials and No. 016 sieve for mineral pore-forming additives. Mixing of the charge was carried out in two stages - first on dry basis, then - after moistening to molding moisture with water at a temperature of $+16 \pm 4{ }^{\circ} \mathrm{C}$. The molding of corpulent samples - cubes $5 \times 5 \times 5 \mathrm{~cm}$. Was carried out in a plastic way. Then the samples were dried at a temperature of $60 \pm 5^{\circ} \mathrm{C}$ to a moisture content of $1-2 \%$. The dried samples were fired at a temperature of $1000 \pm 10^{\circ} \mathrm{C}$ with isothermal exposure for one hour. For comparison, the composition was made from clay raw materials without additives (composition 1).

\section{Results}

The results of physical and mechanical tests of the obtained samples are presented in Table 4.

Table 4. The results of determining the physico-mechanical properties of ceramic samples (method 3 - the introduction of mineral pore-forming additives).

\begin{tabular}{|c|c|c|c|c|c|}
\hline Type of additive & $\begin{array}{c}\text { Composition } \\
\text { number }\end{array}$ & $\begin{array}{c}\text { Additive } \\
\text { content. \% }\end{array}$ & $\begin{array}{l}\text { Average } \\
\text { density. } \\
\mathbf{k g} \backslash \mathbf{m}^{3}\end{array}$ & $\begin{array}{c}\text { Porosity. } \\
\%\end{array}$ & $\begin{array}{c}\text { Compressive } \\
\text { strength. } \\
\text { Rstr.MPa }\end{array}$ \\
\hline No additives & 1 & 0 & 1930 & 22.8 & 13.7 \\
\hline \multirow{3}{*}{$\begin{array}{l}\text { Limestone } \\
\text { dense } \\
\left(\mathrm{CaCO}_{3}\right)\end{array}$} & 2 & 5 & 1790 & 28.4 & 17.5 \\
\hline & 3 & 10 & 1680 & 32.8 & 19.6 \\
\hline & 4 & 15 & 1610 & 35.6 & 16.6 \\
\hline \multirow{3}{*}{$\begin{array}{l}\text { Two-water } \\
\text { gypsum } \\
\left(\mathrm{CaSO}_{4} \times 2 \mathrm{H}_{2} \mathrm{O}\right)\end{array}$} & 5 & 5 & 1780 & 28.8 & 14.2 \\
\hline & 6 & 10 & 1640 & 34.4 & 14.5 \\
\hline & 7 & 15 & 1590 & 36.4 & 12.7 \\
\hline \multirow[t]{3}{*}{ NLMP slag } & 8 & 5 & 1770 & 28 & 13.5 \\
\hline & 9 & 10 & 1750 & 30 & 12.3 \\
\hline & 10 & 15 & 1736 & 31 & 11.7 \\
\hline
\end{tabular}


The resulting porous ceramic samples are the basis for the production of hollow ceramic products. When creating $50 \%$ voids during the molding of products, the average density will decrease to $840-800 \mathrm{~kg} / \mathrm{m}^{3}$, which will provide structural and heat-insulating wall materials of medium density class 0.8 .

\section{Conclusion}

Among the priority tasks of the functioning of "smart" subjects of human life for a long time remains energy conservation. From the standpoint of consumer behavior, it is advisable to consider passive and active approaches to energy conservation. Passive is determined by constructive solutions (use of energy-saving materials and technologies, spatial orientation of buildings, environmental aspects). Active requires the participation of consumers and is provided by tariff incentives and information support. The effectiveness of these approaches is determined by consumer literacy, resource capabilities of the society, the effectiveness of promoting resource-saving decisions by the state.

The analysis showed that the technical characteristics of the building, by definition, less dependent on the volatile behavior of consumers of smart technologies, in conditions of insufficient "smart" literacy and consumer awareness, are more preferable from the point of view of energy saving efficiency than characteristics associated with smart solutions.

As a result of research, it was found that consumers have a passive approach to energy conservation in the "smart home". It is shown that when creating a "smart home", priority is given to multifunctional materials (structural and thermal insulation).

The effectiveness of the use of popular wall structural and heat-insulating materials is analyzed. The rationality of the use of porous ceramic products is shown.

It has been revealed that for the production of ceramic wall structural and heatinsulating materials, the rational method of production is the introduction into the charge of mineral pore-forming additives with plastic molding.

As a result of research, it was found that the use of a mineral pore-forming additive of dense limestone $\left(\mathrm{CaCO}_{3}\right), 15 \%$ in the composition of the charge, allows to reduce the average density of ceramic material by $35.6 \%$. The average density is $1610 \mathrm{~kg} / \mathrm{m}^{3}$, and the compressive strength is $16.6 \mathrm{MPa}$.

From this position, the creation of wall structures of residential buildings using energysaving ceramic materials is promising.

\section{References}

1. J.R. Vazquez-Canteli, S. Ulyanin, J. Kampf, Z. Nagy, Sustainable Cities and Society 45, 243-257 (2019) DOI: 10.1016/j.scs.2018.11.021

2. D.M. Jimenez-Bravo, J. Perez-Marcos, D. De la Iglesia, G. Gonzalez, J.F. De Paz, Energies 12(7), 1317 (2019) DOI: 10.3390/en 12071317

3. E. Avdeeva, T. Davydova, N. Skripnikova, L. Kochetova, Proc. Int. Conf. on SPbWOSCE-2018 "Business Technologies for Sustainable Urban Development”, E3S Web Conf. 110, 10 (2019) DOI: 10.1051/e3sconf/201911002139

4. A. Nilsson, M. Wester, D. Lazarevic, N. Brandt, Energy and Buildings 179, 15-25 (2018) DOI: 10.1016/j.enbuild.2018.08.026

5. S. Abrol, A. Mehmani, M. Kerman, C. Meinrenken, P. Culligan, Proc. Int. Conf. on IEEE 106(4), 661-679 (2018) DOI: 10.1109/JPROC.2018.2791405

6. G.V. Yesaulov, Urban Planning 4, 68-74 (2017) 
7. A. Bhati, M. Hansen, C.M. Chan, Energy Policy 104, 230-239 (2017) DOI: 10.1016 / j.enpol.2017.01.0132

8. S.J. Wang, P. Moriarty, Innovative Solutions for Energy Transitions 158, 3271-3276 (2019) DOI: 10.1016/j.egypro.2019.01.985

9. I. Vassileva, F. Wallin, E. Dahlquist, Energy 46(1), 94-100 (2012) DOI: 10.1016/j.energy.2012.02.069

10. Abasnezhad, N. Soltani, E. Markarian, H.A. Fakhim, H. Khezerloo, Environmental Progress \& Sustainable Energy 38(2), 741-749 (2019) DOI: 10.1002/ep.13106

11. S.B. Sadineni, S. Madala, R.F. Boehm, Renewable \& Sustainable Energy Reviews 15(8), 3617-3631 (2011) DOI: 10.1016/j.rser.2011.07.014

12. G. Battista, L. Evangelisti, C. Guattari, C. Basilicata, R. de L. Vollaro, Sustainability 6(8), 4694-4705 (2014)

13. M. Vlasova, P.A.M. Aguilar, V. Molina, A.T. Estrada, M. Kakazey, Science of Sintering 50(3), 275-289 (2018) DOI: 10,2298/SOS1803275V

14. M.S. Camino-Olea, A. Cabeza-Prieto, A. Llorente-Alvarez, M.P. Saez-Perez, M.A. Rodriguez-Esteban, Proc. Int. Conf. on 3rd World Multidisciplinary Civil Engineering, Architecture, Urban Planning Symposium (WMCAUS 2018) 471, 082059 (2019) DOI: 10.1088/1757-899X/471/8/082059

15. M.A. Katen, R.G. Abakumov, Innovation Economics: Prospects for Development and Improvement 1(6), 81-85 (2015)

16. A.E. Turchenko, E.D. Boeva, Innovation, technology and business 2(6), 5-10 (2019)

17. A.E. Turchenko, I.A. Kurilo, High technology in the construction complex 2, 66-68 (2018) 